\title{
Simulation study of an agile high-speed machining system for automotive cylinder heads
}

\author{
M Omar, K Hussain* and S Wright \\ Department of Mechanical and Manufacturing Engineering, University of Bradford, UK
}

\begin{abstract}
There is a continuous need within most manufacturing environments for more flexible production equipment, particularly where customer satisfaction and responsiveness promote quality improvement. In this paper, an automated agile manufacturing system that uses high-speed computer numerically controlled (CNC) machines to make automotive cylinder heads is proposed and evaluated by means of discrete event simulation using the ARENA simulator. Two alternative agile system configurations are constructed and simulated to achieve the production target. The simulation shows some significant benefits in using the agile system and demonstrates that high-speed $\mathrm{CNC}$ equipment is a viable option for cylinder head manufacture at a production volume of 550000 units per annum. It is shown that the agile system can provide more flexibility and half the throughput time of the transfer line.
\end{abstract}

Keywords: agile manufacturing, flexible machining, cylinder head, CNC, simulation, ARENA, throughput

\section{NOTATION}

$\begin{array}{ll}\text { ARENA } & \text { simulation software } \\ \text { CNC } & \text { computerized numerical control } \\ \text { Conv. } & \text { conveyor } \\ \text { EOQ } & \text { economic order quantity } \\ \text { Hzl } & \text { horizontal } \\ \text { JIT } & \text { just-in-time } \\ \text { LT } & \text { long term } \\ \text { m/min } & \text { metre per minute } \\ \text { Op } & \text { operation } \\ \text { TQM } & \text { total quality management } \\ \text { Utilization } & \text { (machine working time } / \text { machine } \\ & \begin{array}{l}\text { availability time) } \times 100 \\ \text { WIP }\end{array} \\ & \text { work-in-progress }\end{array}$

\section{INTRODUCTION}

Manufacturers need to become more flexible in order to remain competitive. For this reason the mass production system is becoming increasingly inadequate and

The MS was received on 10 December 1997 and was accepted after revision for publication on 15 December 1998.

*Corresponding author: Department of Mechanical and Manufacturing Engineering, University of Bradford, Richmond Road, Bradford, West Yorkshire BD7 1DP, UK. will become obsolete in many industries in the near future. Producers and consumers have altered the way in which goods and services are provided, created, defined and consumed. Although price is still important, other factors have been identified as giving a competitive advantage in the customized market place. Goldman et al. [1] identified the forces that are causing manufacturers to adopt an increasingly flexible production system. These are globalization, shorter product life, market fragmentation, produce to order, convergence of physical products and services, distribution infrastructure and mass customization. Within this context, agile manufacturing has become a very popular concept in recent years. Nagel et al. [2] consider agility to be the ability to move quickly, resourcefully and adaptively to changes in the business environment. Herrin [3] has postulated that agile manufacturing, the next step beyond lean production, will become the essential strategy for dominant organizations of the twenty-first century. Others argue that agility is more than just manufacturing strategy; it is an organizational development that flattens corporate hierarchies, enabling rapid decision making and providing for a greater variety of products. According to Goldman [4], an agile organization must have the capability for:

(a) intense, sustainable and interactive customer relationships, 
(b) rapid cost-effective development of products and production facilities,

(c) continuous improvement of product development,

(d) low variability of volume/unit cost ratio with volume changes,

(e) open electronic access to product data.

Although the definitions of agility and its components varies, the common thread amongst them is the ability of an organization to respond quickly to an environment of continuous and dynamic change in a customer driven market.

Figure 1 shows the four steps required in achieving an agile manufacturing production line [5]. Traditional manufacturing has many serious limitations, as indicated in this figure. Manufacturers have had to adopt various measures such as MRPII, JIT and TQM to gain control. Competition has forced many organizations to refine their production methods and management philosophies even further to reduce inventory, defects, and cost, and to improve quality and productivity.

In common with other manufacturing sectors, along with a trend towards globalization and market fragmentation, the automotive industry is characterized by decreasing product life cycles. Passenger car model ranges are now typically replaced on a three to four year cycle. Frequently there is a large carryover of components and subsystems to the new model range so that the life cycle of major subassemblies, such as engines, is longer. For engines designed in the 1960s and 1970 s life cycles were typically $20-30$ years. However, increased customer demands for improved fuel economy and refinement, coupled with legal require- ments to reduce exhaust emissions, have led to a reduction in engine life cycles. Engines designed in the early 1990s may therefore have lives of only 10 years [6]. Furthermore, it is not unusual for an engine design to be modified several times during its life in order to upgrade or enhance its performance [6].

The major components of an automotive engine (cylinder head, cylinder block, camshaft, crankshaft and connecting rod) are produced by casting or forging processes followed by finish machining and grinding. In the case of cylinder heads, the most complex component, about 100 machining operations are needed to transform the raw casting to the finished component. Historically such machining has been performed using transfer lines composed of a mixture of single- and multispindle machines. For a cylinder head line having an annual throughput of 500000 units, a typical requirement for a major car producer, the level of initial investment is currently about $\$ 40$ million [6]. Based on initial capital investment, transfer lines have, to date, represented the most economic route [6], but these are dedicated systems configured by the supplier to machine a particular product. If a product design changes, e.g. as the result of a mid-life upgrade, this invariably results in scrapping and replacement of individual workstations, each costing typically up to $\$ 3$ million. In addition, once the product is withdrawn from service, the dedicated nature of the associated transfer line prevents its reuse with the replacement product [6] and often a large proportion of the line is scrapped. At the present time, this means that machines are being scrapped long before the end of their useful lives. The lead time to design, manufacture and commission a cylinder head line is approximately three years. Due to
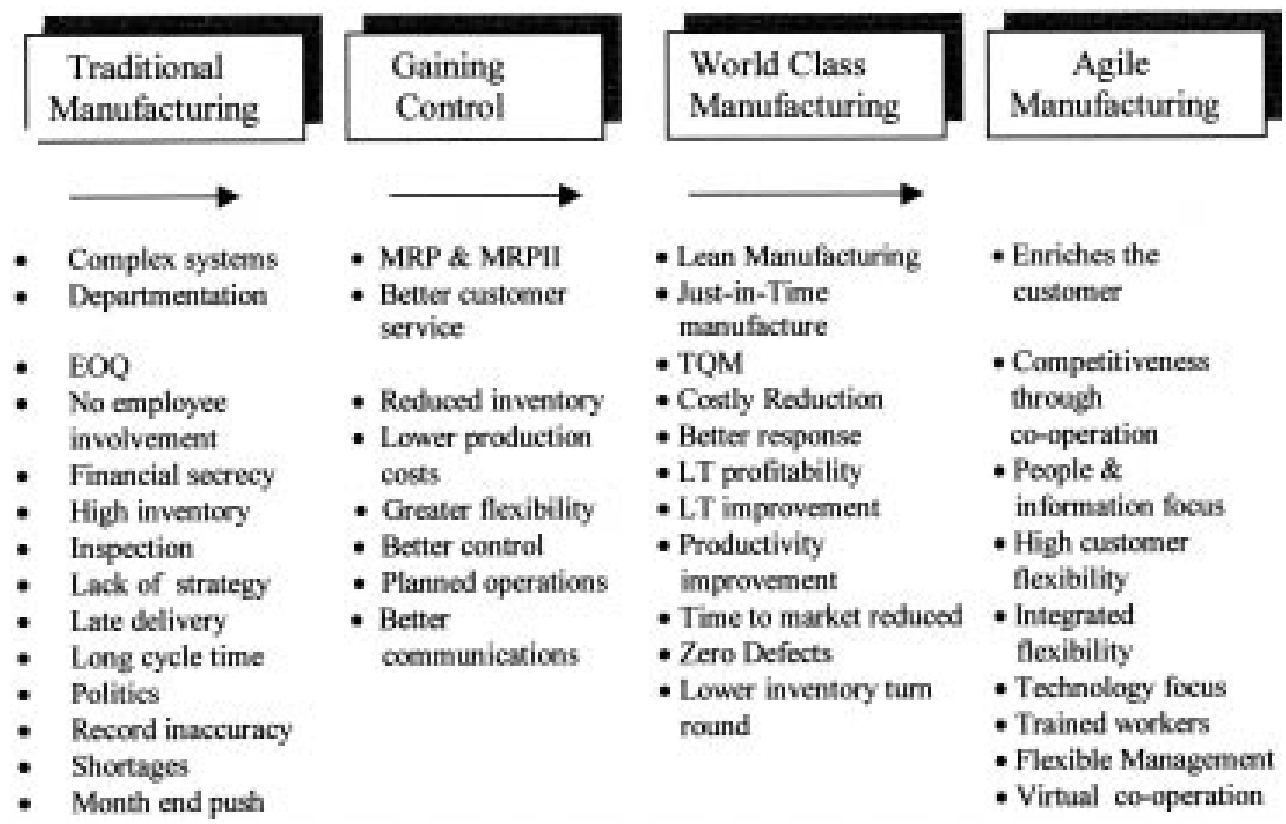

Fig. 1 Steps towards agile manufacturing [5] 
the imprecise nature of long-term forecasting, by the time the line is brought to production, the actual demand may exceed capacity, requiring additional machines to be installed. Alternatively, there may be overcapacity leading to suboptimal operation.

Transfer lines are inflexible systems, well suited to the mass production era of the automotive industry [6], but the industry trend towards shorter product life cycles suggests that a more flexible approach to high-volume manufacture is required. Such a facility should be able to cope with variations in demand through the ability to be reconfigured rapidly to handle a range of products. Also, unlike current transfer lines, the introduction of new products will not require scrapping of the system. Although flexible manufacturing systems based on head-changing multispindle [7] or single-spindle CNC machining centres [8] are already in use for machining engine components, these systems are restricted to production volumes of about 100000 per annum [6]. The reason for this is that non-productive time, e.g. head changing, tool changing, point-to-point traversing and workpiece transport from one workstation to the next, is greater on a transfer line. In recent years, though, cutting speeds and traverse speeds of CNC machines have increased. Traverse speeds, for example, have increased from 10 to $80 \mathrm{~m} / \mathrm{min}$ [9], leading to significant reductions in non-productive time. Knobeloch [10] considers the resultant high-speed CNC machines to be a viable alternative to transfer machine technology for engine production at the rate of $100000-500000$ units per annum. A more recent evaluation by Haynes [6] has shown that the high-speed $\mathrm{CNC}$ option is more economic than transfer lines up to 475000 units per annum, despite having an initial purchase cost up to 50 per cent more than that of a transfer line.

An engine machining facility configured using highspeed CNC machines can be considered to be an example of an agile manufacturing system. The main objective of this paper is to describe the concepts of an agile manufacturing production line and to build and optimize a simulation model for an agile high-speed machining system for automotive cylinder heads.

\section{CYLINDER HEAD TRANSFER SYSTEM}

The cylinder head, which contains the combustion chamber, is one of the major components of a car engine. If several cylinder head types are to be produced, the design of the machining line will be increased in complexity. Therefore, in order to produce different types of cylinder head, flexible systems have become a necessity for most engine manufacturers.

It has been suggested that a production volume of 500000 units per annum is the economic optimum for engine production and that high-volume producers will plan to meet this optimum level whenever possible in their new, expanded or re-equipped facilities in the future [11]. This implies that unless engines can be produced as part of a modular family they must command a sufficiently large market to avoid a considerable cost penalty.

The cylinder head machining system that has been examined here is currently running at a production volume of 550000 units per annum. The transfer process is synchronous; i.e. each part travels through every workstation. The process includes 28 transfer machines, each of which is 15 stations long, and the cycle time is $0.6 \mathrm{~min}$ at 100 per cent efficiency [6]. Therefore, parts on average take $9 \mathrm{~min}$ to be processed through the entire machining system. The transfer machines are linked together by powered roller conveyors, hence the speed of the process is controlled by the slowest machine. The powered roller conveyors hold 10 parts between the transfer machines, requiring 6 min to pass through. Thus the total throughput time for the transfer process is approximately $400 \mathrm{~min}$, assuming no line stoppage.

Because of the lack of space in and around the production line, new machinery has been often placed several metres away from the desired position and is linked to the existing line by powered roller conveyors. While this enables the manufacture of new products, it adds to the throughput time owing to long sections of powered roller conveyors.

\section{AGILE HIGH-SPEED CYLINDER HEAD MACHINING SYSTEM}

The system developed in this paper attempts to overcome the main disadvantage of the use of flexible equipment over transfer lines, which is the production volume limitation of $\mathrm{CNC}$ machines. It achieves this by duplication of CNC workstations.

Figure 2 shows schematically the conceptual agile manufacturing process using standard high-speed CNC milling machines. The process consists of 86 high-speed CNC machines arranged into five operations, 10, 20, 30,70 and 110. Each operation is completed on nonsynchronous machines, which means that parts only pass through one machine per operation.

Each machine can complete the operational process and thus parts are machined on whichever machine becomes available. The quantity of machines and number of cells become functions of production volume rather than of the production process.

Operation 30 is the most complex part of the system as it contains 30 machines, comprising five cells, and a long length of cell automation, as shown in Fig. 2. The overhead gantry automation, which uses linear drives, 


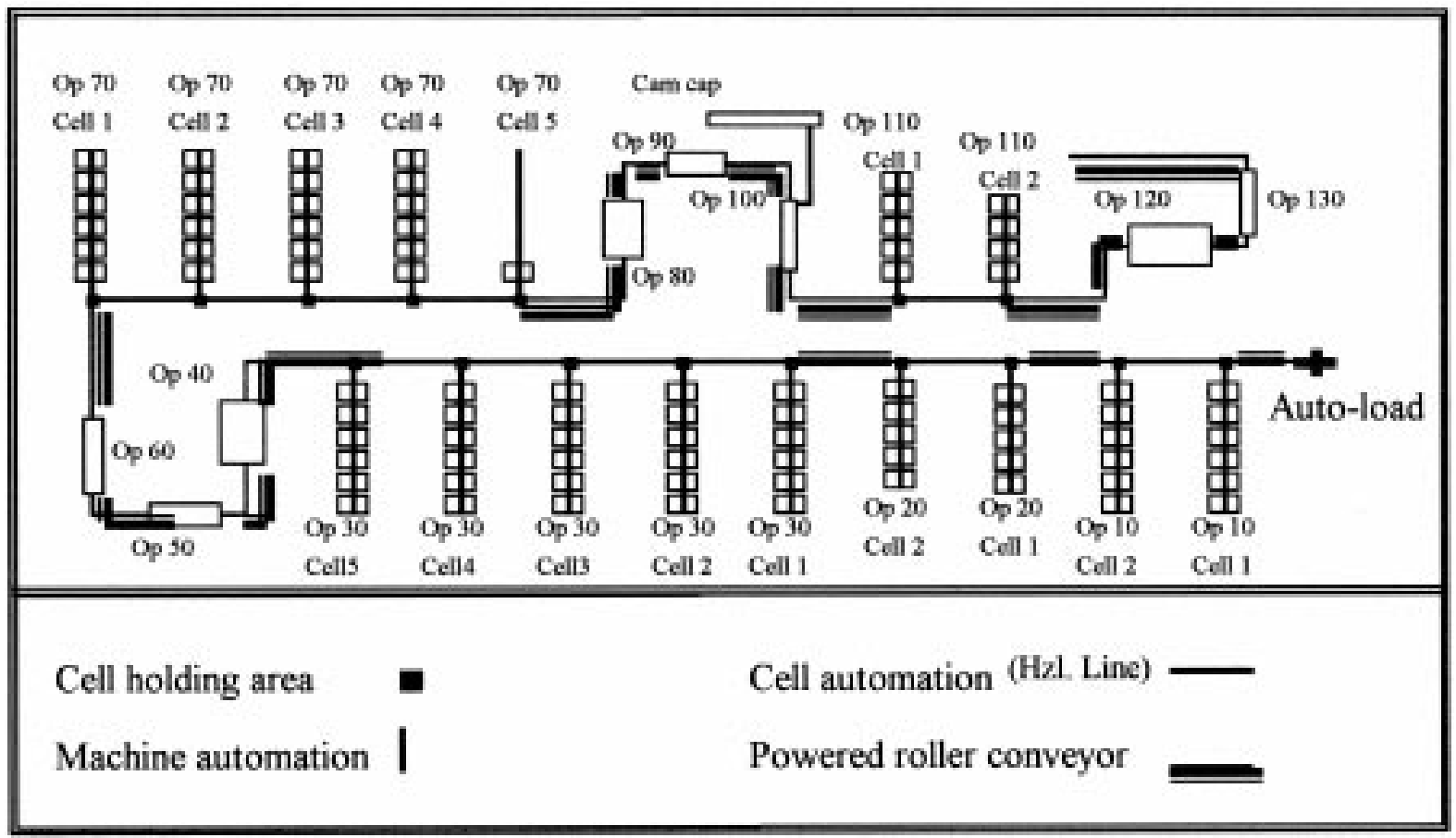

Fig. 2 Agile cylinder head line

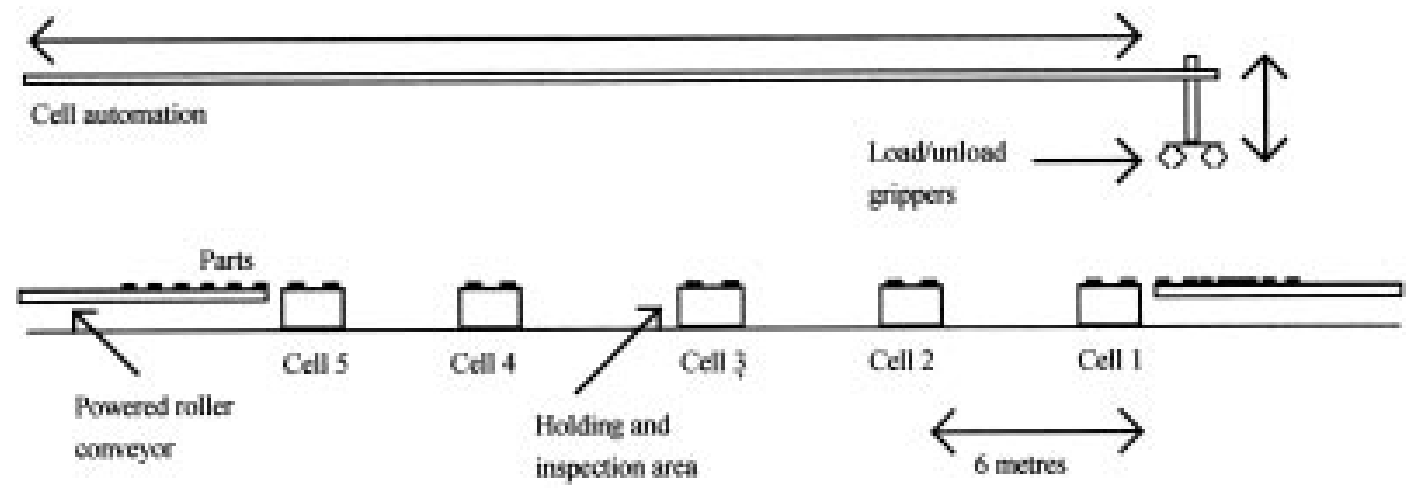

Fig. 3 Vertical section through cell automation of operation 30

can operate at $132 \mathrm{~m} / \mathrm{min}$, which is achievable with current technology. The cycle time for operation 30 is $13.84 \mathrm{~min}$ and thus the machine automation needs to be able to load and unload from the cell holding area to any machine within $0.46 \mathrm{~min}$. The longest distance that the machine automation has to travel is $48 \mathrm{~m}$ from the holding area to the furthest machine and back, as shown in Fig. 3. The optimum time in which the cell automation can complete this procedure is $0.65 \mathrm{~min}$ and hence operation 30 is incapable of meeting the throughput target. Simulation has verified this result, as indicated in Section 4.4.

A typical sequence of events, as shown in Figs 3 and 4, is as follows:

1. The cylinder head moves from the preceding operation via a powered roller conveyor to an escapement at the end of the powered roller conveyor.
2. The cell automation picks up the part from the escapement and places it at the cell holding and inspection area with the shortest queue of parts waiting. A finished part is removed from the cell holding area before the next is added. The holding/ inspection area has enough space for one new part and one finished part.

3. The new part is picked up from the holding area by the machine automation and transferred to the first available machine. The finished part is removed from the fixture by the unload gripper and replaced with the new part by the load gripper. The fixture accurately locates and clamps the part in the machine.

4. Once the grippers are clear of the machine, the cutting cycle begins and the machine automation returns the finished part to the holding area. 
5. The cell automation removes the finished part from the cell holding area and moves it to the next powered roller conveyor.

6. The above process is repeated for the next operation.

However, operations 40, 50, 60,80, 90, 100, 120 and 130 involve the use of traditional transfer machines because these operations require specialized equipment.

\section{SIMULATION OF THE AGILE SYSTEM}

Recent advances in simulation technology have created a greater awareness and use of simulation in industry. There are a number of simulation software packages available for the manufacturing engineer to use. Simulation can be a powerful tool for evaluating the performance of a proposed system and choosing an appropriate design before actually implementing the solutions. In this study, the ARENA simulation package [12] was selected because of its flexibility in modelling many manufacturing situations and its user-friendly modelling environment.

\subsection{Data collection and model input}

From the actual production line, conveyor speeds, distances and the cell automation speed and acceleration/ deceleration were collected. The inter-arrival times were estimated by experimenting with the simulation model. The exponential distribution is a relatively common inter-arrival time distribution, which introduces variation into the mean value of a parameter, and hence it was adopted for this analysis. For the cycle time the triangular distribution was used, which also introduces variability [12]. The $\mathrm{CNC}$ machines are said to be very reliable and therefore it was assumed that the cycle times would vary by only \pm 1 per cent from the modal value.

\subsection{Model building}

Figure 5 shows the basic system logic, which is repeated in each operation. In the main, the incoming conveyor requests the cell automation to transport parts to the specified cell. The cell holding area has space for a single new part arriving at the cell and space for a single finished part leaving for the next operation in the sequence. Hence the cell holding area, as shown in the figure, is split into two sections. The first is to send parts for an available $\mathrm{CNC}$ machine to process, while the second transports finished parts to the next conveyor.

\subsection{Model results and analysis}

The ARENA simulation software was used to model the proposed agile system [6] shown in Fig. 2. The simulation time to run the model was in the range of $30-35 \mathrm{~h}$ to simulate a 1 year production period. A 'warm-up' period was used to achieve steady state conditions.

Results of the initial simulation model, model 1, are given in Table 1. It shows that the proposed system [6] is incapable of meeting the annual production target of 550000 units. Although this initial model does not meet the required throughput level, it has two advantages over the existing transfer system. Firstly, the throughput time for the transfer system is about $400 \mathrm{~min}$ [6] and the average throughput is almost half that for the agile system of $203.12 \mathrm{~min}$. Additionally, the WIP was estimated to be over 600 units for the transfer system, while that of the agile system was an average of 235.90 units.

The average utilization of the transfer machine operations was found to be 65.7 per cent, while the average utilization for the $86 \mathrm{CNC}$ machines was 48.1 per cent. These results can be used as a benchmark for any model modifications.

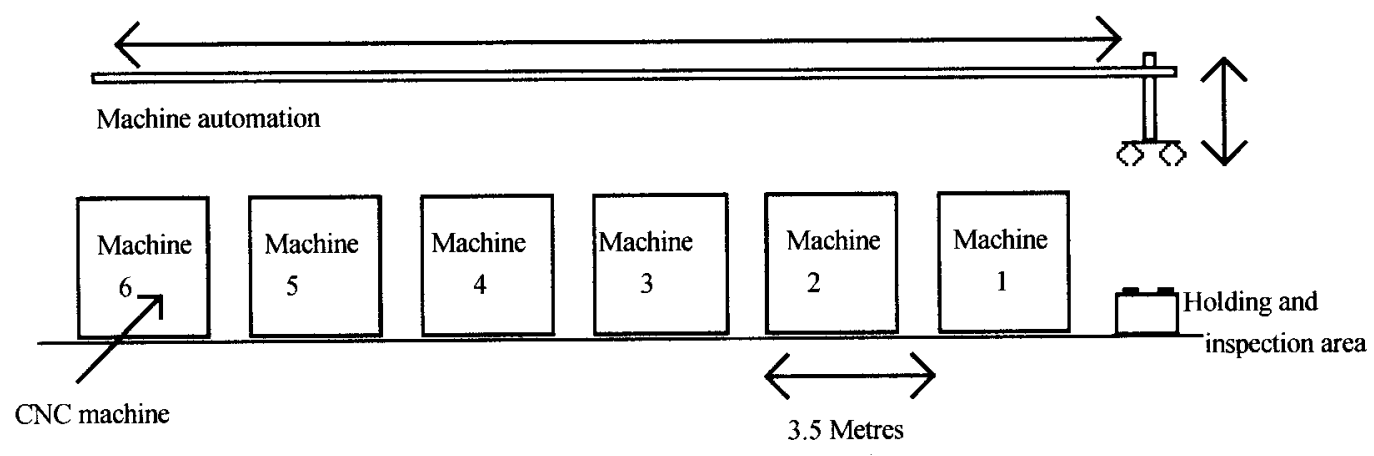

Fig. 4 Vertical section through machine automation of operation 30 


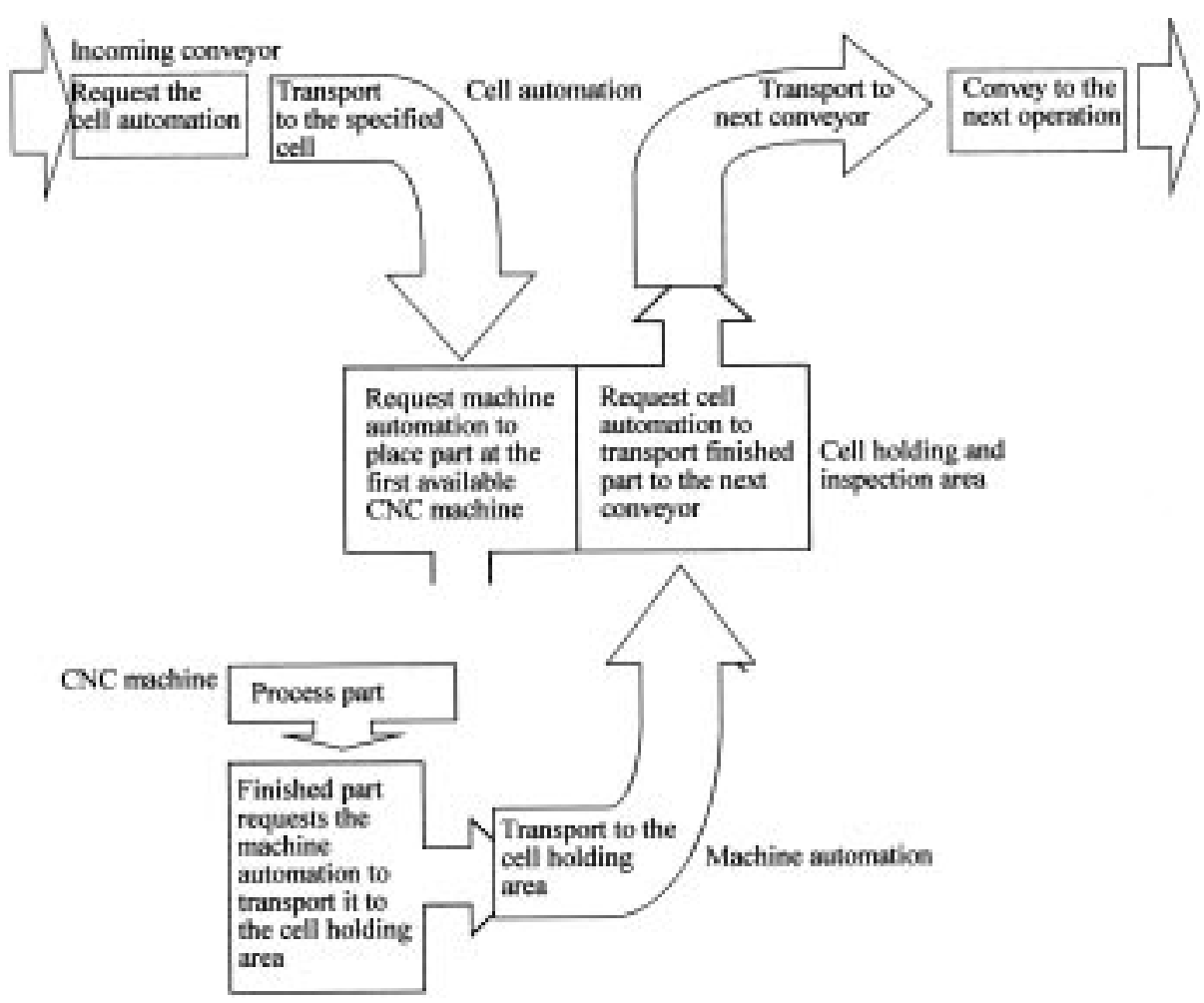

Fig. 5 Flow diagram of system logic

The results also illustrate that operations 30 and 70 , which both consist of five cells, are fully utilized. The cell automation speed is limited to $132 \mathrm{~m} / \mathrm{min}$ and, as expected, it cannot travel fast enough to deal with the required number of units for operations 30 and 70 .

\subsection{Model improvements}

The model system was reconfigured in an attempt to increase the throughput. Two areas for improvement identified are concerned with operations 30 and 70 which both consist of five cells. In essence the problem with model 1 was that the cell automation was incapable of travelling at the necessary speed. However, the speed of the overhead gantry was a constraint that could not be changed. Another constraint was that the handling automation could only travel in straight lines. The maximum possible speed was $132 \mathrm{~m} / \mathrm{min}$ travelling horizontally and $66 \mathrm{~m} / \mathrm{min}$ vertically. Therefore, a viable option was to reduce the distance which the cell automation travelled, bringing the handling areas closer together. The cell automation overhead gantry travels in the $x$ and $z$ direction and, assuming the gripper to travel in the $y$ direction, as shown in Fig. 6b, operation 30 could be reconfigured as shown in Fig. 6a.

The model assumes that the automation speed in the $y$ direction is the same as that for the $z$ direction, i.e. 66 $\mathrm{m} / \mathrm{min}$. Operation 70 was arranged in an identical configuration as operation 30 except that it consisted of five cells of four machines and one cell of five machines.
The remaining operations were set as in model 1 . The reconfiguration reduced the end-to-end distance from $27.5 \mathrm{~m}$ to just $15.5 \mathrm{~m}$ and thus a considerable improvement in the system performance was expected.

The cell holding area in model 2 thus accommodated two cells, as shown in Fig. 6b, with the cell automation overhead gantry in a central position. Taking operation 30 as an example, once the overhead gantry is over the cell holding area, the gripper moves in the $y$ direction to be over the parts for cell 1 or cell 6 before moving down to load/unload a part.

The simulation results for this arrangement are given in Table 1, as model 2. A 22.2 per cent increase in the average throughput over the initial model was achieved, but this was still 15.7 per cent short of the target. Also, the time-in-system increased which violated the goal to maintain the throughput time of the initial model. The

Table 1 Performance parameters

\begin{tabular}{llll}
\hline & Model 1 & Model 2 & Model 3 \\
\hline $\begin{array}{l}\text { Average time-in-system (min) } \\
\text { Average work-in-progress }\end{array}$ & 203.12 & 210.85 & 202.19 \\
$\quad$ (cylinder heads) & 235.90 & 297.68 & 338.57 \\
$\begin{array}{l}\text { Average annual production } \\
\quad \text { cylinder heads) }\end{array}$ & 379454 & 463798 & 549900 \\
Cell automation (\% utilization) & & & \\
$\quad$ Operation 10 & 72.8 & 84.4 & 95.8 \\
$\quad$ Operation 20 & 66.2 & 79.9 & 94.9 \\
$\quad$ Operation 30 & 98.1 & 66.9 & 56.8 \\
$\quad$ Operation 70 & 96.7 & 96.9 & 58.2 \\
$\quad$ Operation 110 & 54.4 & 65.5 & 78.4 \\
\hline
\end{tabular}


a)

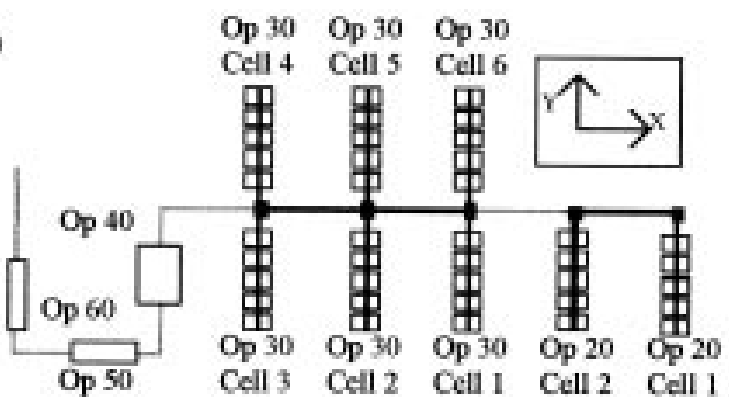

b)

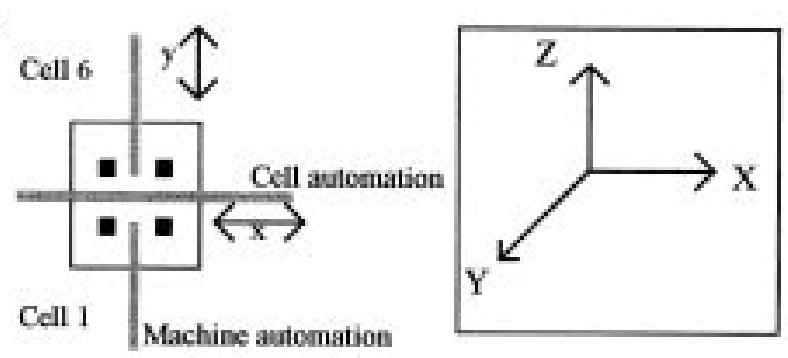

Fig. 6 Model 2, the reconfiguration of operation 30

rise in production from the initial model meant an increase in the WIP as expected. The increased throughput also inevitably meant a rise in the utilization of the transfer machines and the $\mathrm{CNC}$ machines since they were processing more work. The average transfer machine utilization for model 2 rose from 65.7 to 83.9 per cent. The rise in production also led to a rise of 13.3 per cent in the average $\mathrm{CNC}$ machine utilization, from 48.1 to 61.4 per cent.

Another purpose of the changes introduced was to lighten the burden on the cell automation of operations 30 and 70. This was achieved with operation 30 which showed a considerable difference (28.8 per cent less). However, the utilization of the cell automation for operation 70 increased slightly by 0.9 percent.

\subsection{Modified configuration (model 3)}

Model 2 was an improvement on model 1, but the average yearly production was still about 86200 units short of the target value of 550000 units. The next logical development was to reduce the number of cells the automation must serve without increasing the size of the cells.

Figure 7 shows the final proposed modification for operation 30. Operation 70 was also configured in the same manner and the remaining operations were the same. Operations 30 and 70 were both split into two identical cells, each consisting of three machine cells. The robot gripper (see Fig. 8a), picks up the parts from the escapement at the end of the powered roller conveyor coming from operation 20 and distributes the parts equally to the two powered roller conveyors feeding operation 30 . The second robot gripper takes the parts from the two conveyors coming from operation 30 and places them on the conveyor to operation 40, which uses a transfer machine.

An overhead gantry was used instead of the robot gripper, as shown in Fig. 8b. The device has two grippers and a typical sequence of events could be:

1. Gripper 1 picks up a part from conveyor 1 and moves it to conveyor 2 .

2. As the two grippers are connected to each other, gripper 2 is now in position over conveyor 1 . The gripper unloads the part and loads it on to conveyor 3.

3. The grippers are now in their original position and the cycle is repeated.

Using the same speeds for this automation as the existing overhead gantry automation, no additional information was required. The time duration for each activity (load parts, move parts to conveyor 2 or 3 , unload part) was $0.6 \mathrm{~s}$. Therefore the overhead gantry required $1.8 \mathrm{~s}$ to carry out the operation.

In model 3, the average hourly production was 98.761, which was marginally below the production target of 98.779 units $/ \mathrm{h}$, a difference of just 0.018 units $/ \mathrm{h}$. Table 1 shows that the average time-in-system for model 3 was marginally better than for the initial model; 202.19. The rise in the production level also meant a rise in the WIP to an average of 338.57 , which

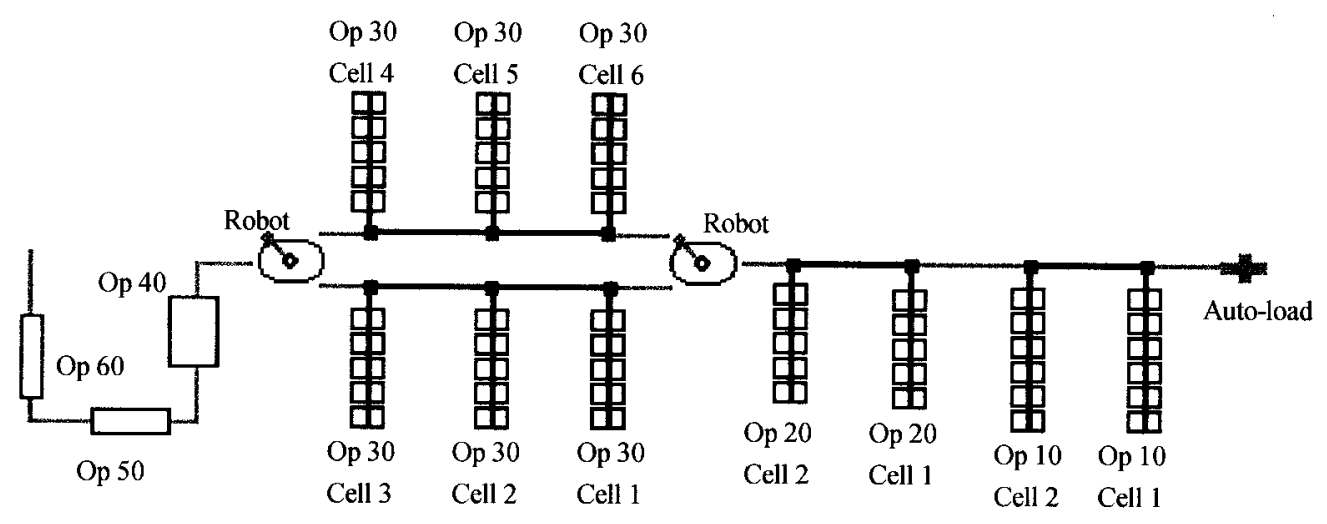

Fig. 7 Modified configuration for operation 30 


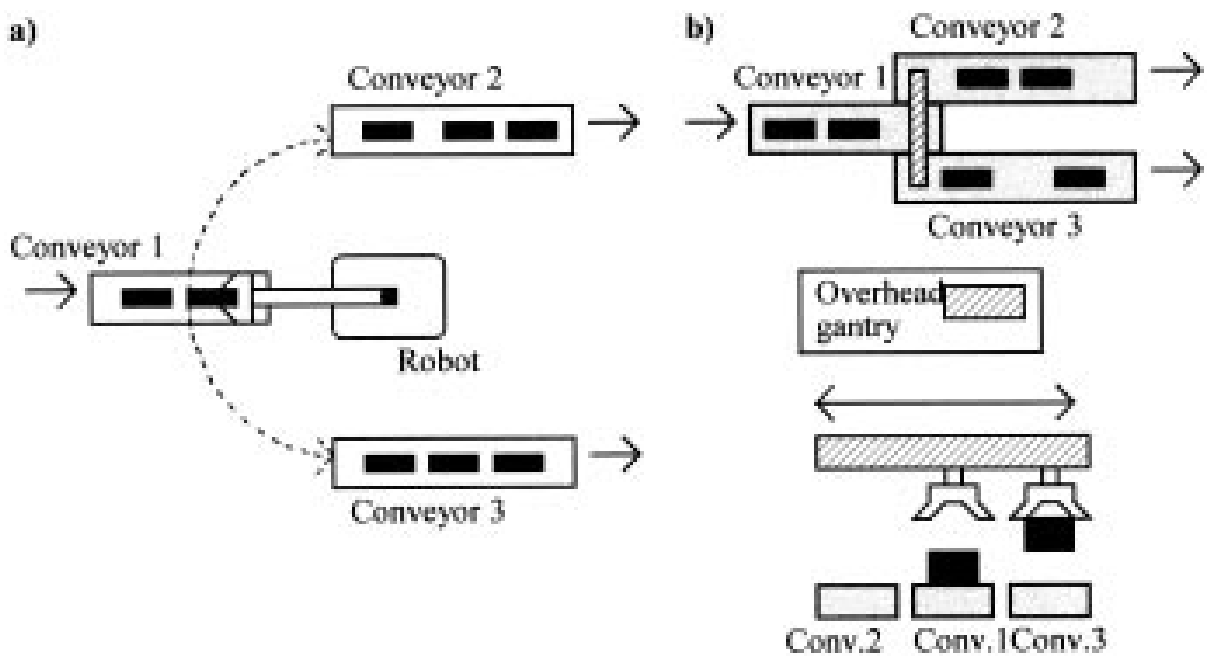

Fig. 8 Robot gripper configuration
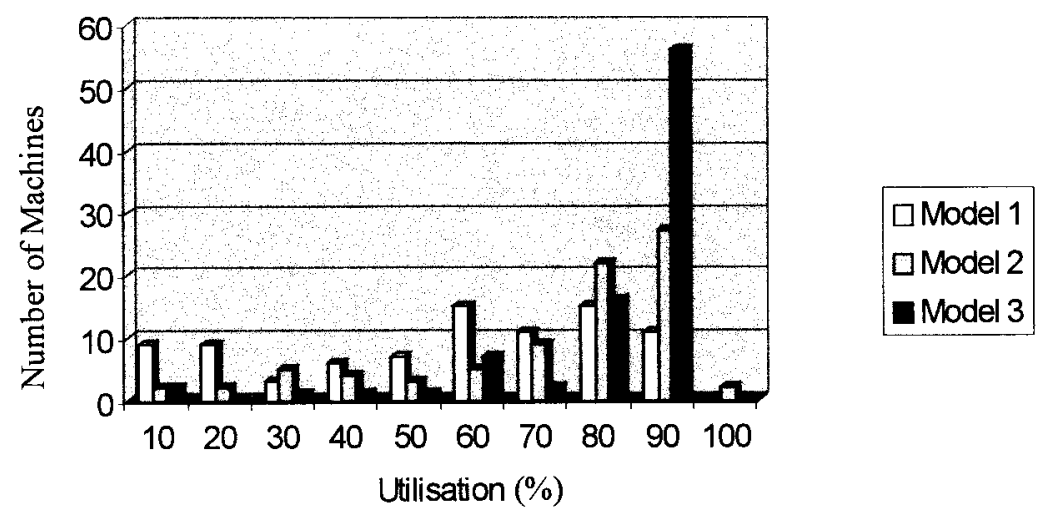

Fig. 9 Overall comparison of machine utilization

was still considerably lower than that of the transfer system. The utilization in model 3 improved from 83.9 per cent for model 2 to 99.4 per cent. The CNC machine utilization also showed an increase, from 61.4 per cent for model 2 to 74.8 per cent for model 3 .

The cell automation utilization figures for operations 10, 20 and 110 all increased, while those for operations 30 and 70 decreased from around 95 per cent in the initial model to just 56 per cent in the final model. The cell automation in operations 30 and 70 operated well within its capabilities.

The initial model (model 1) described was clearly inadequate: operations 30 and 70 involved an end-toend distance that was too much for the cell automation to cope with. Model 2 increased the throughput from 68 to 83 units/h by reducing the end-to-end distance. Model 3 increased the throughput to the target level of 99 units/h by additionally reducing the number of cells to be served by the cell automation.

The WIP is irrelevant when comparing the three system configurations as it rose as expected with the throughput level. However, it is interesting to observe that the throughput time did not vary significantly between the different models and was the lowest for model 3. Figure 9 shows that the machine utilization became increasingly clustered between 70 and 90 per cent utilization as a result of each modification to the initial model.

\section{CONCLUSION}

Traditionally, major engine components such as cylinder heads have been manufactured on transfer lines. Although these lines provide the lowest unit cost at full capacity and entail a lower initial cost, advances in high-speed flexible machining equipment make flexible production an increasingly attractive alternative.

The concept of an agile production line has been described and a simulation study for an agile high-speed machining system for automotive cylinder heads has been built, evaluated and optimized. This has shown that simulation can be usefully applied to this complex system and can predict system performance measures that are difficult to assess with experimentation 
on the physical model. However, the simulation requires data that characterize the behaviour of the system components.

Three simulation models were investigated. The initial model of the agile high-speed cylinder head machining line predicted an average annual throughput of 379454 units per annum, which fell short of the target value of 550000 units. However, the throughput time was half that of the original transfer line. In this model the cell automation simply cannot travel fast enough to cope with greater capacity. Model 2 reduced the maximum distance to be covered by the cell automation, which led to an increase in production to an average of about 470000 units. In model 3, the average annual production was 549900 units, close to the target of 550000 units. The agile system in model 3 had an average throughput time of $202.19 \mathrm{~min}$ compared with about $400 \mathrm{~min}$ for a transfer line.

\section{REFERENCES}

1 Goldman, S. L., Nagel, R. N. and Preiss, K. Agile Competitors and Virtual Organisation: Strategies for En- riching the Customer, 1995 (Von Nostrand Reinhold, New York).

2 Nagel, R. N. and Bhargava, P. Agility: the ultimate requirement for world class manufacturing performance. National Productivity Review, Summer 1994, pp. 331340.

3 Herrin, G. E. Agile manufacturing. Modern Machine Shop, October 1994, 144-146.

4 Goldman, S. L. The agile manufacturing concept. Coupling Technol. to National Need, 1993, 2102(8), 30-40.

5 Omar, M. Simulation study of an agile high speed machining system for cylinder heads. MSc thesis, University of Bradford, 1997.

6 Haynes, N. Engine manufacturing for customer responsiveness. MPhil thesis, University of Bradford, 1997.

7 Miki, T. and Nakao, S. In JASE Conference Proceedings, 1995, paper 9535756, pp. 1-19.

8 Parrish, D. Flexible Manufacturing, 1990 (Butterworth, Oxford).

9 Heisel, U. Ann. CIRP, 1996, 5(1), 389-392.

10 Knobeloch, S. W. Production, January 1994, 106(1), 448 451.

11 Daniels, J. R. New Generation Engines, 1994, pp. 130-137 (The Economist Intelligence Unit Limited).

12 Kelton, W. D., Sadowski, R. P. and Sadowski, D. A. Simulation with ARENA, 1998 (McGraw-Hill). 